Key words: cerebral ischemia; acupuncture-rehabilitation therapy; neurological function;angiogenesis; cIAP1; CD31;rats

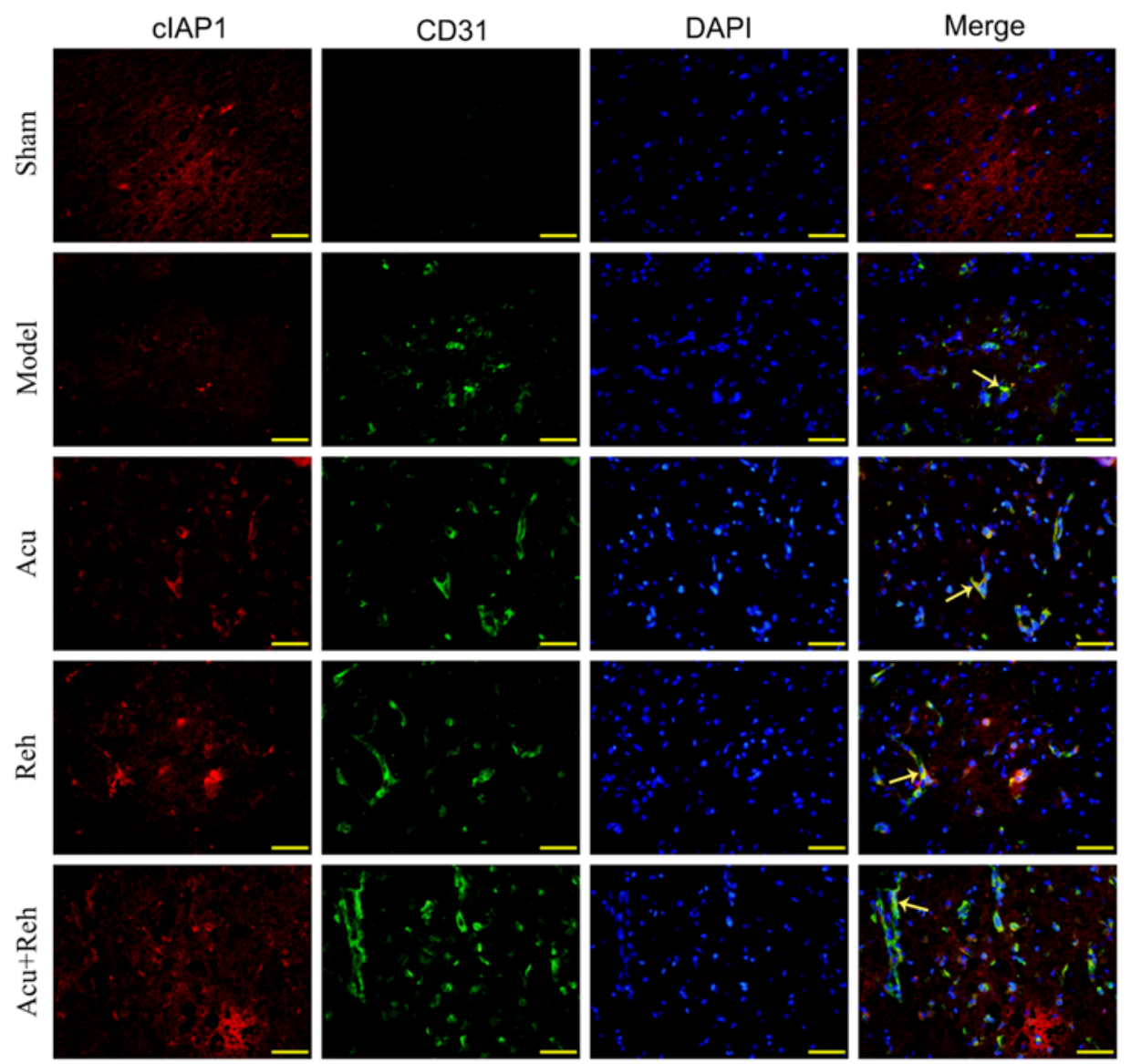

Fig 1 Immunofluorescence double labeling of cIAP1 and CD31

Note: cIAP1(Red), CD31(Green), DAPI(blue). The yellow arrows refer to co-localization cells of cIAP1 and CD31.

UDC 616.018 DOI 10.22448/AMJ.2017.3.109-110

\title{
LOCALIZATION OF CALCIUM CATIONS IN THE LUNGS WITH ANTIORTHOSTATIC HANGING OF RATS
}

\section{Zinoviev S.V., Tseluyko S.S.}

\section{Amur State Medical Academy, Blagoveshchensk, Russia}

Summary. Outbred male rats underwent experimental exposure to hypogravitation for 10 days. It has been established that experimental hypogravitation has a significant effect on calcium metabolism in rat lungs.

Key words: lungs, hypogravitation, calcium cations

Introduction. Weightlessness has a significant effect on calcium metabolism. The features of calcium metabolism in the respiratory organs during weightlessness remain unexplored. The aim of the study was to evaluate the histophysiology of calcium cations in the left lung of rats at the time.

Materialsand methods of research. Theobject of thestudy was outbred male ratsweighing 240 grams attheage of 3 months. The first group is control (10 animals). The second group (10 animals) was subjected to experimental effects of hypogravitation for 10 days [1]. Lungs rats were stained in $5 \%$ alcohol solution of alizarin red C [2]. Cryostat sections were made from lungs rats. Estimation of the color ofalizarin included the calculation of the averagecytochemical coefficientaccording to the formula: $A C C=(4$ ball $\times$ quantity +3 ball $\times$ quantity +2 ball $\times$ quantity +1 ball $\times$ quantity +0 ball $\times$ quantity $/ 100$ Fields of view .

Results of the study. At the beginning of the examination, the organs of the thorax are examined. In the root of lungs rats there are no lymph nodes. Lungs rats drain right and left, caudal mediastinal lymph nodes located along the cranial hollow veins. Visual assessment of the lungs significantly clarifies the assessment of calcification in the lungs, it allows to exclude the infectious process. When staining with alizarin, it was found that in the wall of the caudal vein of the left lung of rats there are 2 layers of cardiomyocytes. Outer layer, longitudinal - 4 rows of cells. Internal, the layer circular - 
4 rows of cells. In the tissues of the lung acinus, alizarin granules appear that mark the localization of calcium cations.

Table 1.

$\begin{array}{lll}\text { Indicator } & \text { Control group } & \text { Hypogravity group } \\ \text { ACC } & 1,1 \pm 0,16 & 0,3 \pm 0,14 p<0,05\end{array}$

Under the influence of hypogravitation on the body of rats, the histochemical reaction is sharply weakened (Table 1). Under the influence of hypogravitation in rats, in most fields of view of the microscope on the lung slices there is a lack of response. In the field of view, single deposits of disintegrated large granules of the reaction product were observed, or small granules $0,2 \mu \mathrm{m}$ in diameter to $0,5 \mu \mathrm{m}$, their amorphous accumulations have a length and a width of less than 5-10 $\mu \mathrm{m}$. In the control group of animals, in the field of view of the microscope, foci of coarse accumulations of alizarin sediment appear, represented by small granules $0.2 \mu \mathrm{m}$ in diameter to $0,5 \mu \mathrm{m}$; they form irregularly shaped zones of alizarin precipitation with a length of 5 to $15 \mu \mathrm{m}$. Separated large granules of the reaction product are noted, in an amount from 5 to 50 , the diameter of the granules is from $0,2 \mu \mathrm{m}$ to $2 \mu \mathrm{m}$.

Conclusion: Experimental hypogravity of the organism has a significant effect on calcium metabolism in rat lungs.

Literature

1. Ilyin E.A., Novikov V.E. A bench for modeling physiological effects of weightlessness in laboratory experiments with rats // Kosm. biol. and air-medicines. 1980. Vol. 24. № 3. P. 79-80.

2. Zinoviev S.V. Histochemical characteristics of the venous bed of the respiratory department of light experimental animals subjected to chronic supercooling after administration of dihydroquercetin into the organism // Bulletin of physiology and pathology of Respiration. 2012. № 45. P. 57-61.

UDC: 616.24-008.444-072.7 DOI 10.22448/AMJ.2017.3.110-111

\section{THE SNORE PHENOMENON AT CHILDREN}

\section{A.A. Blotskiy, V.V. Antipenko, R.A. Blotskiy}

\section{Amur State Medical Academy, Blagoveshchensk, Russia}

Abstrakt. The article gives the reasons for the occurrence of snoring in children. The prevalence of snoring in children in the city of Blagoveshchensk and the Amur Region has been studied. The phenomenon of snoring is revealed in $29 \%$ of children. The authors proposed surgical and conservative options for correcting the phenomenon of snoring. The effectiveness of the techniques reached $86-89 \%$.

Key words: Phenomenon of snoring, obstructive sleep apnea, children.

The snore is known to be the acoustic phenomenon developing in the result of vibration of oropharyngel structures during inhalation in incomplete obstruction of the upper respiratory tract. It occurs in 43 \%of cases of adults. The presence of rhino - and stomatopharyngel hypertrophy in children contribute to the air space decrees of the latters and to appearance of snore phenomenon and syndrome of obstructive sleepy apnoë (SOSA) syndrome. In our literature there are no date touching upon the problems of children's snore in different age groups. There are only some observation on the limited number of patients which do not reflect the importance of this problem.

Determination of epidemiology and prevalence of different chronic disorders contributing to the development of snore in children and elimination it's clinical manifestation with the help of surgical and conservative methods of treatment in the urgent problem at present.

Questionaire among 860 children in different age groups in Blagoveshensk and Amur region was held to study the epidemiology of child snore in different aged groups and to plan special medical aid. It was determined that $29 \%$ of cases of asked children suffer from snore phenomenon, of them $0,6 \%$ suffer from snore phenomenon till the 1 year of age; $22,7 \%$ - till the 1-3 years of age; $28,7 \%$ - till the $4-6$ years of age; $30,3 \%$ - till the $7-11$ years of age; $6,8 \%$ - till the $12-14$ years of age; $10,9 \%$ till the 15-18 years of age. The syndrome of obstructive sleepy apnoë was found in 12 (4,8\%) children suffering from snore.

Of all questionaired children chronic disorders of nasopharyngel organs were revealed in $41,2 \%$ of cases, of them in $290(81,7 \%)$ children chronic disorders of nasopharyngel organs contributed to the development of snore phenomenon. Patients who are older then 10 years with the purpose of diagnostics of anatomy-physiological preconditions of development of snore and syndrome of obstructive sleepy apnoë was carried out a magnetic-resonance tomography.

$72 \%$ of the revealed patients with snore phenomenon and all patients with SOSA were performed surgical and conservative treatment aimed at the elimination of predisposed factors and pathologic processes in nasal cavity, perirhinal sinuses, pharynx and larynx, contributing to the development of the pathology given.

Surgical treatment allowed to eliminate of snore and SOSA in $86,4 \%$ of cases in different aged groups of patients. 